\title{
Short communication: Validation of genomic breeding value predictions for feed intake and feed efficiency traits
}

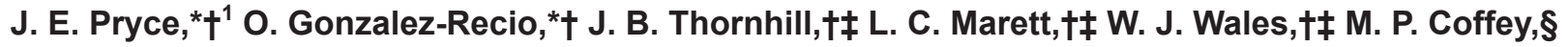 \\ Y. de Haas,\# R. F. Veerkamp,\# and B. J. Hayes* ${ }^{*} l l$ \\ *Biosciences Research Division, Department of Environment and Primary Industries, Agribio, 5 Ring Road, Bundoora, VIC 3086, Australia \\ †Dairy Futures Cooperative Research Centre, Bundoora, VIC 3086, Australia \\ łFuture Farming Systems Research, Department of Environment and Primary Industries, Ellinbank, VIC 3820, Australia \\ §Animal and Veterinary Sciences, Scotland's Rural College (SRUC), Easter Bush Campus, EH25 9RG, Scotland \\ \#Animal Breeding and Genomics Centre of Wageningen University Research Centres (UR) Livestock Research, PO Box 65, 8200 AB Lelystad, \\ the Netherlands \\ IILa Trobe University, Bundoora, VIC 3086, Australia
}

\section{ABSTRACT}

Validating genomic prediction equations in independent populations is an important part of evaluating genomic selection. Published genomic predictions from 2 studies on (1) residual feed intake and (2) dry matter intake (DMI) were validated in a cohort of 78 multiparous Holsteins from Australia. The mean realized accuracy of genomic prediction for residual feed intake was 0.27 when the reference population included phenotypes from 939 New Zealand and 843 Australian growing heifers (aged 5-8 mo) genotyped on high density (770k) single nucleotide polymorphism chips. The $90 \%$ bootstrapped confidence interval of this estimate was between 0.16 and 0.36 . The mean realized accuracy was slightly lower (0.25) when the reference population comprised only Australian growing heifers. Higher realized accuracies were achieved for DMI in the same validation population and using a multicountry model that included 958 lactating cows from the Netherlands and United Kingdom in addition to 843 growing heifers from Australia. The multicountry analysis for DMI generated 3 sets of genomic predictions for validation animals, one on each country scale. The highest mean accuracy (0.72) was obtained when the genomic breeding values were expressed on the Dutch scale. Although the validation population used in this study was small $(\mathrm{n}=78)$, the results illustrate that genomic selection for DMI and residual feed intake is feasible. Multicountry collaboration in the area of dairy cow feed efficiency is the evident pathway to achieving reasonable genomic prediction accuracies for these valuable traits.

Key words: genomic prediction, validation, residual feed intake, feed efficiency

Received August 16, 2013.

Accepted September 25, 2013.

${ }^{1}$ Corresponding author: jennie.pryce@depi.vic.gov.au

\section{Short Communication}

Given the difficulty of obtaining individual animal feed intake phenotypes and the importance of feed costs to the profitability of dairying, interest has been growing in combining DMI phenotype data collected at research farms internationally (Banos et al., 2012; de Haas et al., 2012; Pryce et al., 2012; Veerkamp et al., 2012; Berry et al., 2013). Combined data sets could be used to develop genomic estimated breeding values (GEBV) for feed intake and feed efficiency, which may then be used by industry to select for improved feed efficiency. Pryce et al. (2012) developed a set of genomic prediction equations for residual feed intake (RFI) estimated from phenotypes and genotypes of approximately 1,900 growing Holstein heifers (aged 5-8 mo at testing). de Haas et al. (2012) used DMI phenotypes from both growing calves from Australia and lactating cows from the Netherlands and United Kingdom to derive genomic predictions for DMI. In this study, genomic prediction equations from both studies have been validated in a completely independent cohort of 78 lactating Australian cows.

Seventy-eight cows (all between second and ninth parity) were selected at random from the Ellinbank research herd belonging to the Department of Environment and Primary Industries (Melbourne, Australia). The cows were sired by 32 different bulls, 4 of which had 5 or more daughters in the data set. The cows were genotyped using the Bovine SNP50 Beadchip (Illumina Inc., San Diego, CA). The genotypes were imputed to high density $(632,002)$ SNP using BEAGLE (Browning and Browning, 2009). The same quality control processes described by Erbe et al. (2012) and Pryce et al. (2012) were applied to the genotype data, although a larger reference population was used $(\mathrm{n}=1,783)$, which led to around 1\% more SNP passing quality control. The quality control criteria included overall call rates 
of greater than $95 \%$ and genotype calls with Illumina GenTrain score (Gen-Call) of greater than 0.6. The SNP were also excluded if they were unmapped or mismapped, had duplicate positions, or were located on the Y chromosome. The 609,321 SNP in common with Pryce et al. (2012) were used to calculate GEBV for RFI as GEBV $=\mathbf{X u}$, where $\mathbf{X}$ is a matrix of the cows' genotypes and $\mathbf{u}$ is the vector of SNP effects estimated by BayesMulti (Pryce et al., 2012).

Individual cow daily feed intakes in the validation population of cows were determined using feed bins mounted on load cells that were electronically monitored by linking the intake data to electronic identification of individual cows (Gallagher Animal Management Systems, Hamilton, New Zealand). Cows had ad libitum access to feed and water. In the growing heifer experiment described by Pryce et al. (2012), the growing heifer diets were entirely alfalfa cubes. To be consistent with this, the lactating cows were also fed a diet that consisted mainly of alfalfa cubes, provided by the same manufacturer, Multicube Ltd. (Yarrawonga, Australia), supplemented with crushed wheat fed at milking time.

Following a 14-d adjustment period, the experiment started on February 23, 2013, and continued for $28 \mathrm{~d}$. At the start of the experiment, the 78 cows were 181 (mean) DIM $(\mathrm{SD}=25.2 \mathrm{~d})$. Cows were milked twice daily and milk samples were collected at 6 milkings per week for composition analysis. The cows' mean daily DMI of alfalfa was $19.7 \pm 2.21$ (mean \pm SD) $\mathrm{kg}$. The mean daily intake of crushed wheat was $5.7 \pm 0.83$ (mean $\pm \mathrm{SD}$ ) $\mathrm{kg}$ of DM. To gain statistical power, RFI phenotypes were calculated simultaneously for the 78 cows used in this study combined with records from 112 additional lactating cows, also from the Ellinbank research herd, that, as growing heifers, were part of the experiment described by Pryce et al. (2012). Some of the 112 additional cows had 2 parities of data collected from a total of 3 experiments; 2 of the experiments were with cows in first parity and the other was with the same cows that survived to second or third parity. The total number of records used to estimate RFI was 258. A permanent environmental effect (cow) was fitted to account for animals with repeated records in a repeated measurements linear model, where RFI was the residual term as

$$
\begin{gathered}
\mathrm{DMI}=\mu+\mathrm{DIM}+\text { experiment }+ \text { pregnant }+ \text { parity } \\
+ \text { milk }+ \text { fat }+ \text { protein }+ \text { lactose }+ \text { BW } \\
+ \text { BCS }+ \text { cow }+ \text { RFI }
\end{gathered}
$$

where DMI is the average DMI over the $28 \mathrm{~d}$ experimental period; DIM is DIM at the start of each experiment; experiment was the fixed effect of the experiment $(\mathrm{n}=4)$; pregnant was pregnancy status (scored as pregnant or not pregnant) at the start of the experiment; and parity is the parity group. The 78 cows were assigned to 4 parity groups: parity 3 or less $(\mathrm{n}=9)$, parity $4(\mathrm{n}=20)$, parity $5(\mathrm{n}=29)$, and parities 6 or more $(\mathrm{n}=20)$. Milk, fat, protein, and lactose were the average daily yields $(\mathrm{kg})$ over the 28-d experimental period. Body weight was average daily BW measured using walkover scales of the DeLaval Automatic weigh system (model AWS100, Tumba, Sweden). On average, 20 BW measurements were recorded per cow over the 28-d experimental period. Body condition score was assessed weekly by 4 assessors at different times each week using the 8-point scale described by Earle (1976). A mean BCS of the 4 assessors was recorded per week and averaged over the experimental period. Body condition score was included as a covariate in the model to correct for an approximation of body fat content. A summary of the data of the 78 cows that were used in the rest of this study is presented in Table 1.

\begin{tabular}{|c|c|c|c|c|c|c|c|c|c|c|}
\hline Item & \multicolumn{2}{|c|}{ Parity $\leq 3$} & \multicolumn{2}{|c|}{ Parity 4} & \multicolumn{2}{|c|}{ Parity 5} & \multicolumn{2}{|c|}{ Parity $\geq 6$} & \multicolumn{2}{|c|}{ All } \\
\hline DIM & 186 & 20.0 & 182 & 27.8 & 186 & 24 & 171 & 22 & 181 & 24.5 \\
\hline DMI $(\mathrm{kg} / \mathrm{d})$ & 24.5 & 1.5 & 25.5 & 1.9 & 26.1 & 1.9 & 24.7 & 2.5 & 25.4 & 2.1 \\
\hline $\operatorname{Milk}(\mathrm{L} / \mathrm{d})$ & 20.9 & 3.5 & 23.1 & 3.3 & 22.2 & 2.8 & 21.6 & & 22.2 & 3.1 \\
\hline Fat $(\mathrm{kg} / \mathrm{d})$ & 0.98 & 0.11 & 1.04 & 0.12 & 1.00 & 0.11 & 1.00 & 0.13 & 1.00 & 0.11 \\
\hline BCS (8-point scale) & 4.63 & 0.25 & 4.54 & 0.14 & 4.61 & 0.16 & 4.56 & 0.12 & 4.58 & 0.16 \\
\hline $\mathrm{BW}(\mathrm{kg})$ & 648 & 46 & 646 & 42 & 675 & 43 & 655 & 44 & 659 & 45 \\
\hline
\end{tabular}

Table 1. Means and SD by parity within experiment (28-d duration) average residual feed intake (RFI); DMI; milk, fat, protein, and lactose yields; BCS; and $\mathrm{BW}^{1}$

${ }^{1}$ Parity $\leq 3=7$ of 9 cows pregnant; Parity $4=14$ of 20 cows pregnant; Parity $5=25$ of 29 cows pregnant; Parity $6=16$ of 20 cows pregnant; All $=62$ of 78 cows pregnant. 
For RFI, the genomic prediction equations (calculated using genotypes and phenotypes) were tested using (1) only growing heifers from Australia and (2) growing heifers from Australia and New Zealand as reference populations. Pryce et al. (2012) found that the highest realized accuracies of genomic prediction were obtained by using high-density genotypes and the statistical method BayesMulti (similar to BayesR; Erbe et al., 2012). To make the results comparable to Pryce et al. (2012), BayesMulti genomic predictions were also used in this study.

Using only the Australian heifers in the reference population, the mean realized accuracy, defined as the correlation between the vector of RFI phenotypes and corresponding GEBV, was 0.11. After correcting for the heritability (dividing by the square-root of the heritability of RFI, 0.22 obtained from the study of Pryce et al., 2012), the mean realized accuracy of genomic prediction was 0.25 (Table 2). The correction for the heritability estimate was performed so that the realized accuracy was similar to the correlation between GEBV and true breeding values instead of phenotypes (de Haas et al., 2012; Pryce et al., 2012). When the heifers from New Zealand were added to the reference population, the realized accuracy of genomic prediction of RFI increased to a mean of 0.27 (Table 2). For the analysis that included only Australian heifers in the reference population, some of the correlations of the bootstrapped samples were negative, which is probably due to the comparatively low numbers of animals in the reference population. Encouragingly, the mean correlation (0.27) was $68 \%$ of the accuracy achieved in the cross-validation of growing heifers (0.4; Pryce et al., 2012), suggesting that reduced RFI in lactation can be selected for by using a genomic prediction tool developed in growing heifers. The reduction in accuracy is not surprising because lactating cows have additional energy requirements compared with growing heifers and are physiologically mature.

A second analysis was conducted using the genomic predictions from de Haas et al. (2012) based on DMI phenotypes to predict DMI in the validation populations (instead of RFI). The reference population included a multicountry mixed age group reference population that comprised 843 Australian growing heifers,
359 lactating cows from the United Kingdom, and 599 lactating cows from the Netherlands. Genotypes from these animals, in addition to the genotypes from the 78 lactating cows from Australia, were used to calculate a genomic relationship matrix using the methodology of Yang et al. (2010). A total of 30,594 SNP were used in the genomic relationship matrix that were also used in the high-density SNP genotypes described earlier and the 30,949 SNP used by de Haas et al. (2012). The G-REML (i.e., ASReml; Gilmour et al., 2009) implemented with a genomic relationship matrix, was used to estimate GEBV (de Haas et al. 2012). The inverse of the genomic relationship matrix was used in a model to predict genomic breeding values that included phenotypes for Australian growing heifers and lactating cows from the Netherlands and United Kingdom, but excluded the phenotypes for the 78 validation experiment Australian cows. Phenotypes for DMI were calculated for the 78 lactating cows as the mean DMI over the experimental period of 28 d (i.e., the total DMI of alfalfa plus cracked wheat) so that they could be used to evaluate the realized accuracies of genomic prediction. Dry matter intake was precorrected for fixed effects (DIM, pregnancy status, and the 4 levels of parity groups described in the RFI model) such that the analysis was consistent with de Haas et al. (2012). The accuracy of genomic prediction was calculated as the Pearson correlation between the corrected phenotype and GEBV (realized accuracy) and the same correlation was corrected for heritability $\left(\mathrm{h}^{2}=0.342\right)$ to make the results directly comparable to estimates published by de Haas et al. (2012). As with the previous analysis, a $90 \%$ CI was calculated using bootstrapping with 1,000 replicates. The current study used several models in the analyses, including three univariate models comprising data from (1) 843 Australian growing heifers, (2) 359 lactating cows from the United Kingdom, and (3) 599 lactating cows from the Netherlands, as well as multicountry models comprising data from each country, where country was a separate trait.

Realized accuracies of genomic prediction for DMI using univariate models after dividing by the squareroot of the heritability ranged between 0.25 (United Kingdom reference population) and 0.49 (Dutch reference population; Table 3). The highest accuracies in

Table 2. Realized accuracy ( $\mathrm{r}$ ) of published genomic predictions for genomic EBV for the phenotype residual feed intake (RFI) using BayesMulti (Pryce et al., 2012) in 78 multiparous lactating Australian cows and the realized accuracy corrected for the square root of the heritability $(\mathrm{r} / \mathrm{h})^{1}$

\begin{tabular}{lll}
\hline Reference population & \multicolumn{1}{c}{$\mathrm{r}$} & \multicolumn{1}{c}{$\mathrm{r} / \mathrm{h}$} \\
\hline 843 Australian heifers (AUS) & $0.11(-0.05$ to 0.25$)$ & $0.25(-0.11$ to 0.53$)$ \\
AUS and 939 New Zealand heifers & $0.13(0.08$ to 0.17$)$ & $0.27(0.16$ to 0.36$)$ \\
\hline
\end{tabular}

${ }^{1}$ The 5 th and 95 th percentiles of the bootstrapped distribution are shown in parentheses. 


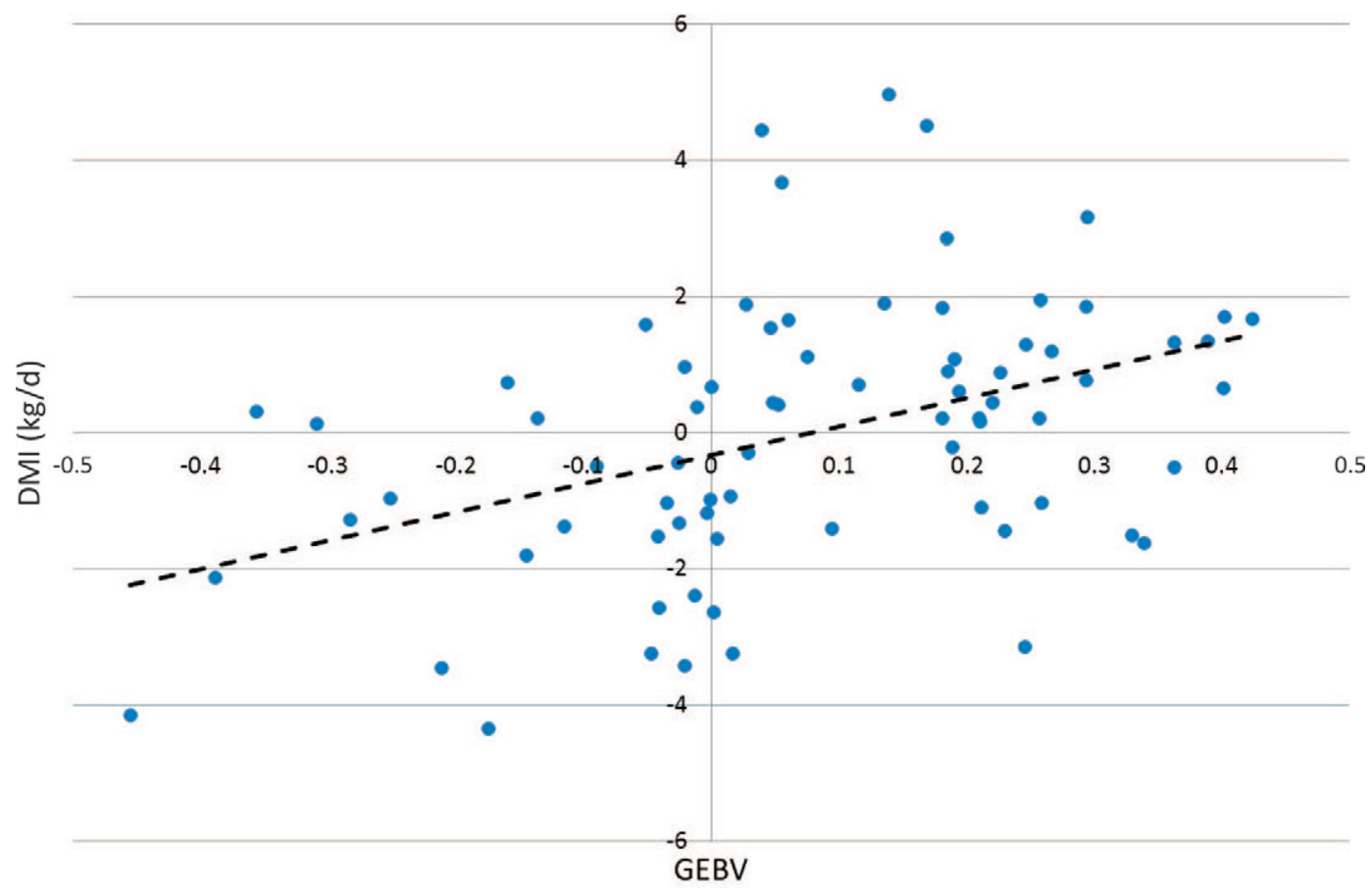

Figure 1. Genomic estimated breeding values (GEBV) for DMI calculated for 78 Australian lactating cows using a multicountry prediction model where 3 populations were included in the reference population (from Australia, the Netherlands, and the United Kingdom) as predictors of Australian lactating cow DMI phenotypes corrected for fixed effects (DIM, pregnancy status, and parity). The dotted line is the regression of DMI on GEBV, where DMI $=4.2, \mathrm{GEBV}=-0.32$, and $\mathrm{R}^{2}=0.18$. Color version available in the online PDF.

the study of de Haas et al. (2012) were achieved using a multicountry analysis, where phenotypes from each country were treated as different traits. The multicountry analysis generated 3 sets of genomic predictions for validation animals on the scales of each of the 3 countries. The accuracy of DMI GEBV for the 78 validation cows was higher (0.7; Table 3$)$ when the genomic breeding values were expressed on the Dutch scale (which was also observed in the univariate analysis). The corrected DMI phenotypes were visually compared with their corresponding GEBV to assess whether the correlations were influenced by a few data points. An example of one of these is shown in Figure 1 for GEBV calculated using the multicountry model expressed on the Dutch scale. These results demonstrate that genomic predictions derived for DMI collected in 2 European countries can be used to predict DMI in Australian lactating cows with reasonable accuracy. The highest accuracy reported by de Haas et al. (2012) for the multicountry analysis was 0.48 , which was lower than the accuracies presented here. This could be due to population sampling, as the data set used for valida-

Table 3. Realized accuracies (r) of published genomic predictions for genomic EBV for the phenotype DMI using genomic REML (de Haas et al., 2012) in 78 multiparous lactating Australian cows and the realized accuracy corrected for the square-root of the heritability $(\mathrm{r} / \mathrm{h})^{1}$

\begin{tabular}{llll}
\hline Model & $\begin{array}{l}\text { Reference } \\
\text { population }\end{array}$ & r & r/h \\
\hline Single country & AUS & $0.26(0.08$ to 0.42$)$ & $0.45(0.13$ to 0.73$)$ \\
Single country & NLD & $0.30(0.09$ to 0.49$)$ & $0.49(0.15$ to 0.83$)$ \\
Single country & UK & $0.15(-0.02$ to 0.33$)$ & $0.26(-0.03$ to 0.57$)$ \\
Multicountry & AUS + NLD + UK & AUS $=0.36(0.2$ to 0.51$)$ & AUS $=0.62(0.34$ to 0.87$)$ \\
& & NLD $=0.42(0.27$ to 0.55$)$ & NLD $=0.72(0.45$ to 0.95$)$ \\
& & UK $=0.40(0.21$ to 0.56$)$ & UK $=0.68(0.36$ to 0.96$)$ \\
\hline
\end{tabular}

${ }^{1}$ The 5 th and 95 th percentiles of the bootstrapped distribution are shown in parentheses.

${ }^{2}$ AUS $=843$ Australian heifers; NLD $=599$ Netherlands lactating cows; UK $=359$ UK lactating cows.

${ }^{3}$ The multicountry analysis generated 3 sets of genomic predictions for validation animals, one on each country scale. 


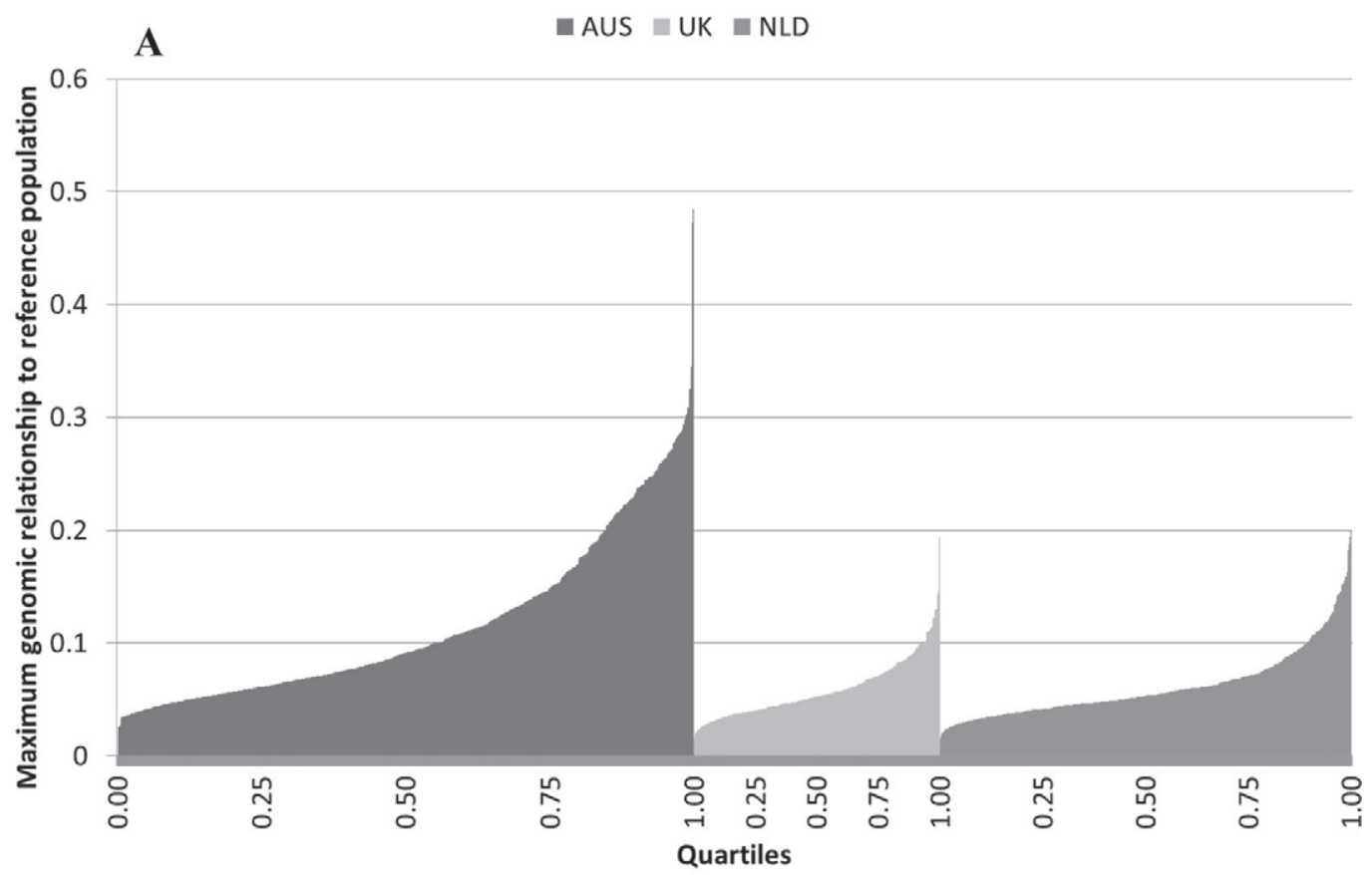

B

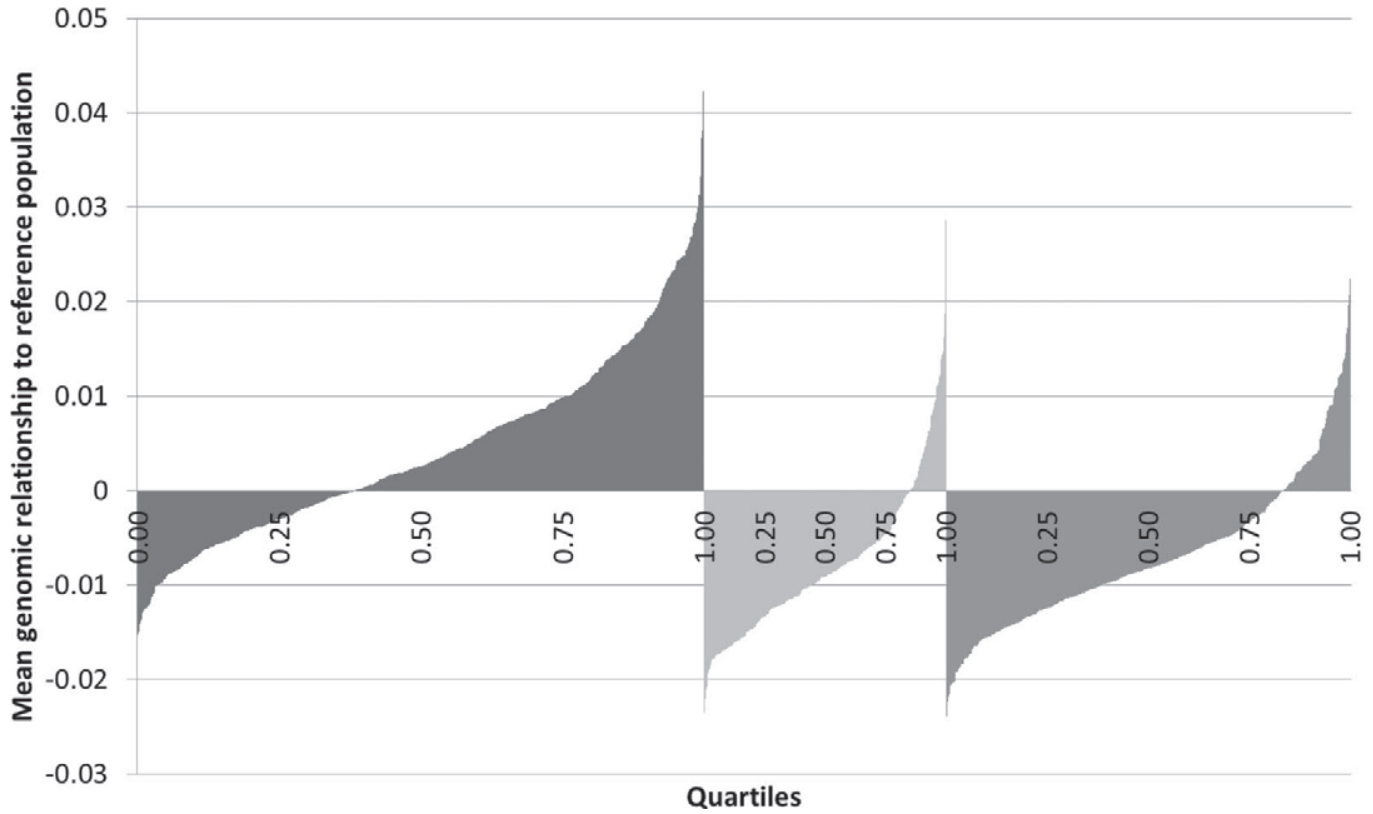

Figure 2. Genomic relationships of validation experiment animals (78 lactating dairy cows) to the reference populations for deriving genomic prediction equations from Australia (AUS), United Kingdom (UK), and the Netherlands (NLD). (A) Maximum genomic relationship (i.e., maximum value of row $i$ in the genomic covariance matrix between validation cow $i$ and reference population animals) ordered from smallest largest value. (B) Mean relationship (i.e., average value of the row $i$ in the genomic covariances matrix between validation cow $i$ and animals in the reference population) ordered from smallest largest value.

tion comprised only 78 cows. The $90 \%$ CI presented in Table 3 suggest that the correlation between DMI phenotypes and corresponding GEBV could be in a broad range. Therefore, although the results presented here are promising, with accuracies of up to 0.72 (Table 3), they should be treated cautiously until more animals are evaluated.

To check that the accuracies reported in Table 3 were not a result of unexpectedly high genomic relationships between reference and validation populations, the 
maximum (Figure 2A) and mean (Figure 2B) genomic relationships between the 78 cows and the reference population used by de Haas et al. (2012) were assessed. As expected, the Australian lactating cows had the strongest genomic relationships with the Australian growing heifers (on average 0.0042) and the weakest with the United Kingdom population (on average -0.0078), which were similar to the Dutch population. Therefore, it was surprising that higher accuracies were achieved using the Dutch reference population compared with the Australian reference population (Table 3). This is in contrast to the results of Pszczola et al. (2012), where the highest accuracies of genomic prediction were achieved when the reference and validation populations were more related. However, the studies are not really comparable, as the Dutch cows in the reference population were lactating whereas the Australian heifers (in the reference population) were only around 6 mo of age. Thus, it appears that the age when phenotypes are measured is more important than strength of relationship and, consequently, a genomic selection tool based on lactating cow DMI is a better predictor of lactating cow DMI than using growing heifer DMI.

The global Dry Matter Initiative (Berry et al., 2013; Veerkamp et al., 2013) aims to accumulate a large reference population by combining genotype and phenotype information from international research populations. The results presented here are encouraging, as they suggest that data from several countries could be combined to realize reasonable accuracies for genomic predictions of DMI. A large upcoming research project will match genotypes of around 6,000 animals from 10 research herds with their phenotypes (Berry et al., 2013) to assess the accuracy of genomic prediction of DMI in a larger population. Using this larger population may resolve the large CI observed in this study due to the small number of animals used.

Validation of genomic breeding values for RFI in 78 lactating Australian cows gave an accuracy of 0.27 when the reference population included 939 New Zealand and 843 Australian growing heifers genotyped at high density. The $90 \%$ CI of this estimate ranged between 0.16 and 0.36 . For the same validation population, GEBV for DMI had an accuracy of up to 0.72 when the multicountry model included lactating cow phenotypes from 2 countries (958 cows from the Netherlands and United Kingdom) and 843 Australian growing heifers. Therefore, although the validation population was small, the results indicate that genomic selection for feed efficiency and feed intake traits is feasible.

\section{ACKNOWLEDGMENTS}

The authors thank the Gardiner Foundation (Melbourne, Australia) and Dairy Futures Cooperative Re- search Centre (Melbourne, Australia) for funding this research. Funding for this research from the Dutch Dairy Board (Zoetermeer, the Netherlands) is acknowledged. United Kingdom feed intake data collection was funded by the Scottish Government. We also thank Elizabeth Ross (Department of Environment and Primary Industries, Melbourne, Australia) for constructive comments on an earlier version of this manuscript.

\section{REFERENCES}

Banos, G., M. P. Coffey, R. F. Veerkamp, D. P. Berry, and E. Wall. 2012. Merging and characterising phenotypic data on conventional and rare traits from dairy cattle experimental resources in three countries. Animal 6:1040-1048.

Berry, D. P., M. P. Coffey, J. E. Pryce, Y. de Haas, P. Lovendahl, N. Krattenmacher, J. J. Crowley, Z. Wang, D. Spurlock, K. A. Weigel, K. A. Macdonald, and R. F. Veerkamp. 2013. International genetic evaluations for feed intake in dairy cattle. Pages 52-57 in Proc. Interbull Annual Mtg., Nantes, France. Interbull No. 47. Interbull, Uppsala, Sweden.

Browning, B. L., and S. R. Browning. 2009. A unified approach to genotype imputation and haplotype phase inference for large data sets of trios and unrelated individuals. Am. J. Hum. Genet. $84: 210-223$.

de Haas, Y., M. P. L. Calus, R. F. Veerkamp, E. Wall, M. P. Coffey, H. D. Daetwyler, B. J. Hayes, and J. E. Pryce. 2012. Improved accuracy of genomic prediction for dry matter intake of dairy cattle from combined European and Australian data sets. J. Dairy Sci. 95:6103-6112.

Earle, D. 1976. A guide to scoring dairy cow condition. J. Agric. (Victoria) 74:228-231.

Erbe, M., B. J. Hayes, L. K. Matukumalli, S. Goswami, P. J. Bowman, C. M. Reich, B. A. Mason, and M. E. Goddard. 2012. Improving accuracy of genomic predictions within and between dairy cattle breeds with imputed high density SNP panels. J. Dairy Sci. 95:4114-4129.

Gilmour, A. R., B. J. Gogel, B. R. Cullis, and R. Thompson. 2009. ASReml User Guide Release 3.0. VSN International Ltd., Hemel Hempstead, UK.

Pryce, J. E., J. Arias, P. J. Bowman, S. R. Davis, K. A. Macdonald, G. C. Waghorn, W. J. Wales, Y. J. Williams, R. J. Spelman, and B. J. Hayes. 2012. Accuracy of genomic predictions of residual feed intake and 250 day bodyweight in growing heifers using 625,000 SNP markers. J. Dairy Sci. 95:2108-2119.

Pszczola, M., T. Strabel, H. A. Mulder, and M. P. L. Calus. 2012. Reliability of direct genomic values for animals with different relationships within and to the reference population. J. Dairy Sci. 95:389-400.

Veerkamp, R. F., M. P. Coffey, D. P. Berry, Y. De Haas, E. Strandberg, H. Bovenhuis, M. P. L. Calus, and E. Wall. 2012. Genomewide associations for feed utilisation complex in primiparous Holstein-Friesian dairy cows from experimental research herds in four European countries. Animal 6:1738-1749.

Veerkamp, R. F., J. E. Pryce, D. Spurlock, D. P. Berry, M. P. Coffey, P. Løvendahl, R. van der Linde, J. Bryant, F. Miglior, Z. Wang, M. Winters, N. Krattenmacher, N. Charfeddine, J. Pedersen, and Y. de Haas. 2013. Selection on feed intake or feed efficiency: A position paper from gDMI breeding goal discussions. Pages 15-22 in Proc. Interbull Annual Mtg., Nantes, France. Interbull No. 47. Interbull, Uppsala, Sweden.

Yang, J., B. Benyamin, B. P. McEvoy, S. Gordon, A. K. Henders, D. R. Nyholt, P. A. Madden, A. C. Heath, N. G. Martin, G. W. Montgomery, M. E. Goddard, and P. M. Visscher. 2010. Common SNP explain a large proportion of the heritability for human height. Nat. Genet. 42:565-569. 